\title{
tomography.
}

In order to obtain the midline echogram the transducer made by 1 or $2 \mathrm{Mc}$./ sec. of barium titanate plate was set above the auricle, then ultrasonic beam transmitted to the rolling pens trace on the potassium jodide starch paper.

So far, we could identify shift of midline echograms 13 out of 14 cases of intracranial hematomas and 13 out of 14 cases of supratentorial tumors.

In case of intracranial tomogram, 1 or $2 \mathrm{Mc}$./sec. of transducer and receiver were set in the tubes $20 \mathrm{~cm}$. of height filled by water. The attachment surfaces were covered by rubber pads. These tubes can be shifted vertically and moved horizontally on the fixed axis, so continuous ultrasonic activity traced on the paper without magnification (Fig. 1). Tomographic echograms were made first confirm the midline echograms setting these tubes above the auricle then move along the coronal and horizontal plane. Irregular trace lines showed in 4 out of 9 cases of intracerebral gliomas (Fig. 2), 1 out of 10 cases of subdural hematomas and a case of anterior parasagittal meningioma correspond to the mass lesions, 4 cases of cerebellar tumors (Fig. 3 ) and a case of pinealoma showed enlarged lateral and third ventricles.

\section{Positive Contrast Cerebral Vintriculography Using Water-Soluble Media}

\author{
Nobuo Moriyasu, Koten Satoh, Fumio Mryauchi, Hiroshi Asano, \\ Shyu Nishio, Tanehiko Mryamoto and Katsuhisa Yamada \\ Department of Neurosurgery, Nihon University School of Medicine
}

Positive contrast human ventriculograms were made with methylglucamine iothalamate $60 \%$ (NMG 10th).

The toxicity of NMG 10th was first tested in animals. Excessive doses of NMG 10th injected either into the cerebral ventricles or cortex produced convulsions and were lethal. Dogs were, however, well tolerated against the injection of $300 \mathrm{mg} / \mathrm{Kg}$ of NMG 10 th into the cerebral ventricles. The minimal lethal dose was $200 \mathrm{mg} / \mathrm{Kg}$ in mice and rats injected in the cerebral cortex.

In clinical cases, a total of 15 ventriculograms were carried out in 12 patients, 5 males and 7 females, between 3 months and 55 years old. Four to $20 \mathrm{ml}$. of NMG 10th was diluted with the same to twice volume of ventricular fluid, injected into the ventricle through ventricular puncture within 30 to 60 seconds, and lateral and straight axial radiographs were taken in rapid succession. Then accurate visualization of the ventricular system (lateral, third, aqueduct of sylvius, fourth nd cisterna magna) was achieved not only clearly, but also stereotactically with the contrast. The best visualization was produced immediately after the 
injection. It shows the precise placement of mass lesions in the ventricle, diencephalon or cerebellopontile angle, and also disturbance of the cerebral fluid circulation.

The examination with NMG 10th containing radioactive iodine $\left({ }^{131} \mathrm{I}\right)$ revealed the remarkable decrease immediately after the injection and the gradual decrease in 20 minutes. The measurement by a scintillation counter near the heart showed a slight mound in 10 minutes and then the gradual upward curve. The radioactive content in blood revealed peak in 15 minutes to one and a half hours, while in urine it was excreted much in 4 to 6 hours.

Complications of ventriculography using NMG 10 th were mild fever, nausea, headache and leukocytosis. Since it is most dangerous when the medium is injected into the cerebral cortex ,it is emphasized to make sure the needle was in the ventricle and to inject without force after dilution with the cerebral fluid.

Positive contrast ventriculography with NMG 10 th results to produce accurately, briefly in method, rapidly in excretion and with little complications as compared with the previously available media.

\title{
Discussion to 109.
}

\section{On Ventriculography with Water-Soluble Contrast Media}

\author{
Yasuhiro Yonekawa and Yasuaki Yoshida \\ Department of Neurosurgery, Faculty of Medicine, Kyoto University
}

We have performed Conray-ventriculography on 16 cases since October 1966. Indications are mainly for thalamic, third ventricular \& infratentorial tumor \& aqueductal stenosis. The method is as follows; in cases of aqueductal stenosis or infratentorial tumor, the tip of a Nelaton's catheter is inserted into third ventricle similarly to central P.V.G., in cases of third ventricural or thalamic tumor, the tip is stopped around foramen Monroi. Then, roentgenograms are taken with injection of 2 c.c. of $60 \%$ Conray previously mixed with 3 c.c. of C.S.F. into ventricular system.

From our experiences Conray ventriculography are suitable for the following cases.

1) Adequate findings have not been obtained from any other examinations, in cases of thalamic, third ventricular tumor or infratentrial tumor are suspected.

2) Those cases under general inhalation anesthesia or children who cannot take prone position, so it is difficult to take central P.V.G.

3) Those cases in which it is difficult or unable to insert the tip of a catheter into the third ventricle. 